\title{
Cocaine Induced Posterior Inferior Cerebellar Artery Stroke Causing Inverted Vision
}

\author{
Vinodh T Doss*, Josh Lennon and Mansour Afshani \\ Department of Neurology, University of Tennessee Health Science Center, Memphis, TN, USA
}

Submission: April 06, 2018; Published: August 16, 2018

*Corresponding author: Vinodh T Doss, Department of Neurology, University of Tennessee Health Science Center, Memphis, TN, USA; Email:vdoss@vt.edu

\begin{abstract}
Introduction: Disorders of visual perception are well known to occur in posterior circulation strokes. Visual field defects are common and are a component of the NIHSS. Other deficits to name a few include visual agnosias, achromatopsia, illusions and hallucinations. These deficits are almost exclusively due to cortical lesions in the occipital lobe or its border zones. Inverted vision, or upside-down vision, is a very rare presentation of stroke.
\end{abstract}

Case Presentation: We report a case of a 57-year-old African-American male who presented with one week of vertigo and inverted vision after inhaling cocaine. He suffered a stroke to the PICA distribution of the left cerebellum.

Conclusion: There are few case reports of inverted vision with ischemic stroke and the pathophysiology is not well understood. Stroke is a leading cause of death and disability especially when involving the posterior circulation. This case highlights the importance of recognizing that this spatial perception disorder could be part of a vertebrobasilar syndrome. It reinforces the few cases reported and adds credence to this location, the cerebellum, which may help define this poorly understood phenomenon.

Keywords: Posterior Circulation; Stroke; Presentation; Occipitallobe; Vertigo; Syndrome; Reinforces; Cerebellum; Phenomenon; Pathophysiology; Disability; Disorder; Hallucinations; Patients; Seldom; Dizziness; Headache; Tamsulosin

\section{Introduction}

Stroke is the third leading cause of death and disability in the United States. Posterior circulation strokes account for approximately twenty percent of ischemic strokes. They are considerably worrisome given that the mortality rate is as high as 80 percent in basilar artery occlusions. Disability can be multisystem due to the proximity of cerebellum and brainstem leaving patients with unilateral or sometimes bilateral motor impairment, visual dysfunction, dysphagia and/or ataxia. Inverted vision, Room Tilt Illusion (RTI), or tortopsia is a very rare presentation of stroke. RTI is the perception of one's visual surrounding rotated 90 to 180 degrees. There have been cases reported of varying etiologies. Stroke has been commonly seen in disorders of visual perception, but the cerebellum is seldom included.

\section{Case Presentation}

The patient is a 57-year-old left-handed African American male with a history of hypertension, cocaine, tobacco and alcohol abuse, and previous left basal ganglia lacune five years ago with no residual deficits. He presented to the emergency department with a one-week history of dizziness, headache, and difficulty walking which had been getting progressively worse. He complained of associated vomiting, inability to sit up straight without support, and had reverted to crawling secondary to unsteadiness when walking. He had some increased weakness in his right leg. He also complained of a visual phenomenon where everything appeared inverted 180 degrees, as if people were "walking on the ceiling." His inverted vision significantly affected his ability to ambulate steadily. He was able to read significantly more fluently when the material was upside-down rather than right-side up. A thorough review of systems was otherwise negative. The patient's family history was remarkable for coronary artery disease and diabetes. His social history was significant for regular heavy alcohol use, one pack per day smoking history, and occasional cocaine use. The patient later admitted to using cocaine within the week prior to presentation and no other illicit drugs. His home medications included lisinopril, amlodipine, gabapentin and tamsulosin.

On examination, he was mildly hypertensive, with otherwise normal vital signs. Visual acuity was $20 / 25$ in both eyes. Pupils were $2-3 \mathrm{~mm}$ and reactive bilaterally with no papillary afferent defect. Intra-ocular pressure was normal. Visual fields were 
full to confrontation in both eyes. Extra-ocular movements were intact bilaterally. There was no evidence of head tilt, ocular torsion, skew devation. Dilated fundoscopic examination revealed normal cup-to-disk ratio and no retinal abnormalities. Motor examination was normal except for a right leg drift and 4/5 hamstring strength on the right. He had right sided hemianesthesia to pinprick and temperature, including face. Reflexes were symmetric. There was no dysmetria. Gait was steady with the use of a rolling walker and he did drift to the left on Romberg testing. NIH stroke scale was 2, for right leg drift and right hemibody sensory deficit.

\section{Investigations}

Complete blood count and comprehensive metabolic panel were normal. A urine drug screen was positive for cocaine. Total cholesterol was 155, with an LDL of 71. RPR screen was nonreactive and HIV screen was negative. Hemaglobin A1c, thyroid stimulating hormone, and homocysteine were normal. Transthoracic echocardiogram was unremarkable. A CT of the head without contrast demonstrated chronic ischemic disease in the basal ganglia, white matter, and a hypodensity within the left cerebellum. Magnetic resonance imaging of the brain without contrast revealed an acute ischemic infarct within the left inferior cerebellar hemisphere in addition to scattered remote lacunes with sparing of the occipital cortex. Magnetic resonance angiography of the head and neck demonstrated occlusion of the left PICA.

\section{Discussion}

Inverted vision is a rare presentation of posterior circulation strokes. The pathogenesis and affected anatomical sites are not well understood. This visual phenomenon has been reported with lesions involving the parietal and occipital cortices as well as the vestibular-cerebellar system. The cerebellum specifically has been cited in a few case reports, but this disorder of spatial perception is rare [1-7]. Visual distortions in space and time have been studied in saccadic movements, but the effects of lesions outside the visual cortex have not been well studied [8]. There may be a common pathway involved with skew deviation and inverted vision suggested in one study implicating the otolith dysfunction [8].

Inverted vision has previously been described in relation to encephalitis and cranial trauma [9]. Multiple sclerosis [7,10,11], epilepsy, Susac syndrome, after a third ventriculostomy [1215], and frontal lobe disease have also been reported. Previous reports have indicated a loss of the "inversion effect" of facial recognition for patients with prosopagnosia [16]. However, the severity of visual deficits obviously varies and the patient we report here had no identifiable deficit in ability to recognize faces, either inverted or upright. Individuals wearing prism glasses to induce 180degree inverted vision have reported functional adaptation to seeing upside-down within a week [17]. Our patient also functionally adapted and was able to ambulate steadily with a rolling walker. Given that initially there were no objective signs on initial examination except for body tilt this was likely partly due to otolithic dysfunction [18]. At 3 month follow up visit, he continued to describe his vision as a sustained inverted vision at approximately 180 degrees which is longer than previous reports. On Romberg testing his sway had improved but was still present. He had continued to adapt, including holding all reading material upside down but was walking independently.

\section{References}

1. Ropper AH (1983) Illusion of the tilting of the visual environment. Report of five cases. J Clin Neur Ophtalmol 3(2): 147-151.

2. Steiner I, Shahin R, Melamed E (1987) Acute 'upside down' reversal of vision in transient vertebrobasilar ischemia. Neurology 37(10): 16851686.

3. Mehler MF (1988) Complete visual inversion in vertebrobasilar ischaemic disease. J Neurol Neurosurg Psychiatry 51(9): 1236-1237.

4. Stracciari A, Guarino M, Ciucci G, Pazzaglia P (1993) Acute upsidedown reversal of vision in vertebrobasilar ischaemia. J Neurol Neurosurg Psychiatry 56(4): 423.

5. Charles N, Froment C, Rode G, Vighetto A, Turjmann F, et al. (1992) Vertigo and upside-down vision due to an infarct in the territory of the medial branch of the posterior inferior cerebellar artery caused by dissection of a vertebral artery. J Neurol Neurosurg Psychiatry 55(3): 188-189.

6. Hernández AH, Pujadas F, Purroy F, Delgado P, Huertas R, et al. (2006) Upside down reversal of vision due to an isolated acute cerebellar ischemic infarction. J Neurol 253(7): 953-954.

7. Siegel AM (1988) Inverted vision in MS. Neurology 38(8): 1335.

8. Binda P, Cicchini GM, Burr DC, Morrone MC (2009) Spatiotemporal distortions of visual perception at the time of saccades. Journal of Neuroscience 29(42): 13147-13157.

9. Walsh FB, Hoyt WF (1969) Clinical neuro-ophthalmology. Williams \& Wilkins, Baltimore, USA 1: 753-754.

10. Dogulu CF, Kansu T (1997) Upside-down reversal of vision in multiple sclerosis. J Neurol 244: 461.

11. Okuyucu EE, Okuyucu S, Karazincir S, Akoglu E, Duman T (2008) Acute 'upside-down' visual inversion due to multiple sclerosis. Mult Scler 14(2): 266-267.

12. Ringel RA, Brick JF, Riggs JE (1988) Upside-down epilepsy: a manifestation of second sensory seizures. South Med J 81(11): 1466.

13. Zeidman LA, Melen O, Gottardi-Littell N, Getch C, Alberts MJ, et al. (2004) Susac syndrome with transient inverted vision. Neurology 63(3): 591.

14. Pamir MN, Ozer AF, Siva A, Ozek MM, Kansu T (1990) 'Upside down' reversal of vision after third ventriculostomy. Journal of Clinical NeuroOpthalmology 10(4): 271-272.

15. Solms M, Kaplan-Solms K, Saling M, Miller P (1988) Inverted vision after frontal lobe disease. Cortex 24(4): 499-509.

16. de Gelder B, Rouw R (2000) Paradoxical configuration effects for faces and objects in prosopagnosia. Neuropsychologia 38(9): 1271-1279.

17. Linden DEJ, Kallenbach U, Heinecke A, Singer W, Goebel R (1999) The myth of upright vision. A psychophysical and functional imaging study of adaptation to inverting spectacles. Perception 28(4): 469-481.

18. Kamper L, Rybacki K, Mansour M, Winkler SB, Kempkes U, et al. (2008) Time management in acute vertebrobasilar occlusion. Cardiovasc Intervent Radiol 32(2): 226-232. 
This work is licensed under Creative Commons Attribution 4.0 Licens

DOI: 10.19080/OAJNN.2018.08.555733
Your next submission with Juniper Publishers will reach you the below assets

- Quality Editorial service

- Swift Peer Review

- Reprints availability

- E-prints Service

- Manuscript Podcast for convenient understanding

- Global attainment for your research

- Manuscript accessibility in different formats

( Pdf, E-pub, Full Text, Audio)

- Unceasing customer service

Track the below URL for one-step submission https://juniperpublishers.com/online-submission.php 